\title{
Robust interconnected automated control system for improving reliability of the turbine-generator unit shaft in food industry enterprises
}

\author{
Serhii Baliuta, Valerii Kuievda, Iuliia Kuievda \\ National University of Food Technologies, Kyiv, Ukraine
}

\begin{abstract}
The shafts of the turbine generator units are adversely affected by disturbances of the connected power system, which can be reduced by the use of an automated control system.

On the basis of the system analysis of turbine-generator unit (TGU) control process, the requirements for the automated control system of TGU were formulated and its functional model was created. The main purpose of this control system is to increase the reliability of TGU in terms of assessment and reduce the adverse impact of the power system on TGU's shaft material under uncertainty.

The subsystems of robust interconnected automated control system of TGU (RI ACS TGU) and their interaction within the system are described. RI ACS TGU consists of shaft monitoring systems, robust interconnected regulator of TGU, identification of control plant model, automatic control of shaft rotational oscillations.

Conclusions. The structure and composition of RI ACS TGU has proposed. RI ACS TGU allows improving the damping properties of TGU in perturbations of the electrical system operating modes under conditions of uncertainty by using the methods of robust control and taking into account the mutual influence of generator excitation control system and steam turbine governing system.
\end{abstract}

Key words: turbine-generator, automation, robust, control.

Corresponding author: Iuliia Kuievda

E-mail: julika@gmail.com

DOI: $10.24263 /$ RES-2019-4

\section{Introduction}

As a result of electric power system (EPS) disturbances and interaction of the turbine-generator unit (TGU) with EPS, mechanical torsional vibrations occur in the TGU shaft, which cause the accumulation of fatigue damage of the TGU shaft material, significantly reduce the TGU life cycle and its reliability, and what is more, lead to its early decommissioning [Error! Reference source not found., Error! Reference source not found., 12].

For damping low-frequency electromechanical oscillations and ensuring EPS stable operation, TGUs are equipped with generator excitation control system (ECS) and 
steam turbine governing system (TGS). These control systems are generally designed as separate independent subsystems and do not always provide effective damping of TGU shaft torsional vibrations. There are cases when certain ECS and TGS adjustment parameters caused the excitation of torsional vibrations in the TGU shaft [Error! Reference source not found.].

One of the reasons for decreasing rotational speed control quality and poor damping of the shaft torsional oscillations is that the control systems of the turbine and the synchronous generator, having common input control signals, are not only designed, but also adjusted separately. The problem of coordinating the work of TGS and ECS was solved, for example, in $[4,10]$ by creating methodologies for matched adjustment of these regulators. However, these approaches, without using methods of robust control, do not guarantee obtaining control system with taking the uncertainties of controlled object into consideration. In [Error! Reference source not found.] the authors proposed a new solution to the problem of coordinating the operation of ECS and TGS by using an additional interconnected robust controller. The synthesis of this controller was performed using robust control methods, taking into account the fact that the TGU operation in the power system occurs under conditions of uncertainty due to changes in the TGU parameters in different modes of its operation.

The implementation of this regulator requires the development of a set of related technical solutions that can be implemented by creating an appropriate automated control system (ACS) of TGU, which it will be part of. Thus, the purpose of this work is to determine the functions, place in the thermal power plant (TPP) ACS, the designing of the ASC TGU structure on the principles of interconnectivity and robustness. The main purpose of ASC TGU is supposed to provide high-quality damping of torsional and low-frequency electromechanical oscillations of the shaft line in uncertainty conditions for reducing the accumulation of fatigue damage of the TGU shaft material and ensuring its durability.

\section{Materials and methods}

Methods of system analysis were used by authors to solve the set of formulated tasks within the problem of ASC TGU development. As a result of the system analysis, the factors that influence the torsional oscillations and the shaft durability, their mutual connection, were identified.

System analysis of TGU control processes allowed developing approaches to ASC TGU design, which will provide structuring and integrity of the control process and operation coordination of its individual subsystems and functions.

\section{Results and discussion}


The control functions of the individual components of TGU in the existing systems are performed by the automated control system of technological process of the power unit (ACS TP PU), which includes TGU [Error! Reference source not found.]. In this case, the components of TGU, such as turbine and turbine generator act as separate unconnected control plants with autonomous automatic control systems, the control signals to which are generated directly from ACS TP PU. The logic of control of the turbine (T) and the turbine generator (TG) is combined at the level of ACS TP PU to accomplish such complex control tasks that require the participation of all components of the power unit, including boiler unit (BU), such as starting and stopping processes, etc. However, there are control tasks that relate only to TGU subsystems that can be combined at a separate level in the control hierarchy. One of these tasks is to control the reliability of the shaft of a turbine unit, one part of which relates to $\mathrm{T}$ and another to TG.

To solve this problem, it is proposed to create a robust interconnected automated control system of TGU (RI ACS TGU) with the monitoring function of fatigue damage of the TGU shaft material, which includes TGU control subsystem (CSS TGU) with an automatic interconnected regulator (AIR). The place of this system in ACS TPP is shown in Figure 1.

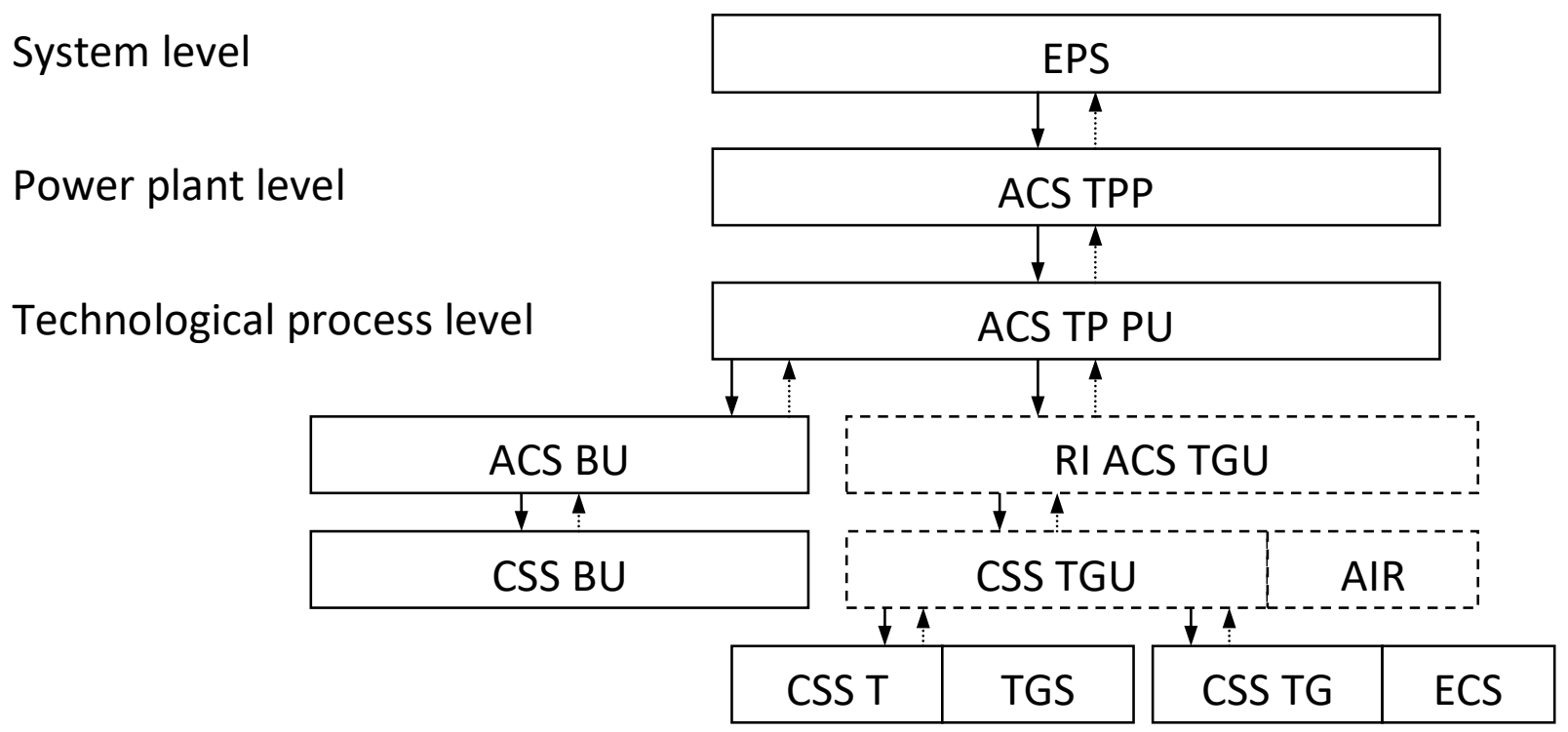

Figure 1. Place of RI ACS TGU in ACS TPP structure

Let's distinguish the functions performed by RI ACS TGU: robust interconnected control of the rotation speed of the TGU shaft; monitoring of fatigue damage of the shaft material; control of the operation of special equipment related to the damping of TGU shaft torsional oscillations: devices for compensating the torsional vibrations, which are capable of creating additional torque. The following functions are proposed to be implemented by means of the respective functional subsystems:

- subsystem of robust interconnected control of TGU; 
Resource and Energy Saving Technologies of Production and Packing of Food Products as the Main Fundamentals of Their Competitiveness: Proceedings of the 8th International Specialized Scientific and Practical Conference, September 12, 2019. Kyiv, Ukraine

- control plant identification model subsystem;

- subsystem of automatic control of TGU shaft torsional oscillations;

- monitoring the TGU shaft state subsystem;

- subsystem of identification of TGU shaft mechanical parameters.

Functional structure of RI ACS TGU is shown in the scheme in Figure 2. As it can be seen from Figure 2, subsystems receive data from a sensor data processing system that statistically processes data in real time, preparing them for calculations. The robust, interconnected shaft speed control subsystem sends control signals to AIR, which through separate TGS and ECS control channels act on their actuators and regulators. The AIR can be reconFigure d from the automated workstation (AW) of the power unit dispatcher, which sends the appropriate command to the robust interconnected control subsystem that triggers the reconfiguration using the control plant identification subsystem data. The control plant identification subsystem uses in its work the identification algorithm of the control plant matrix transfer function proposed by the authors in [Error! Reference source not found.].

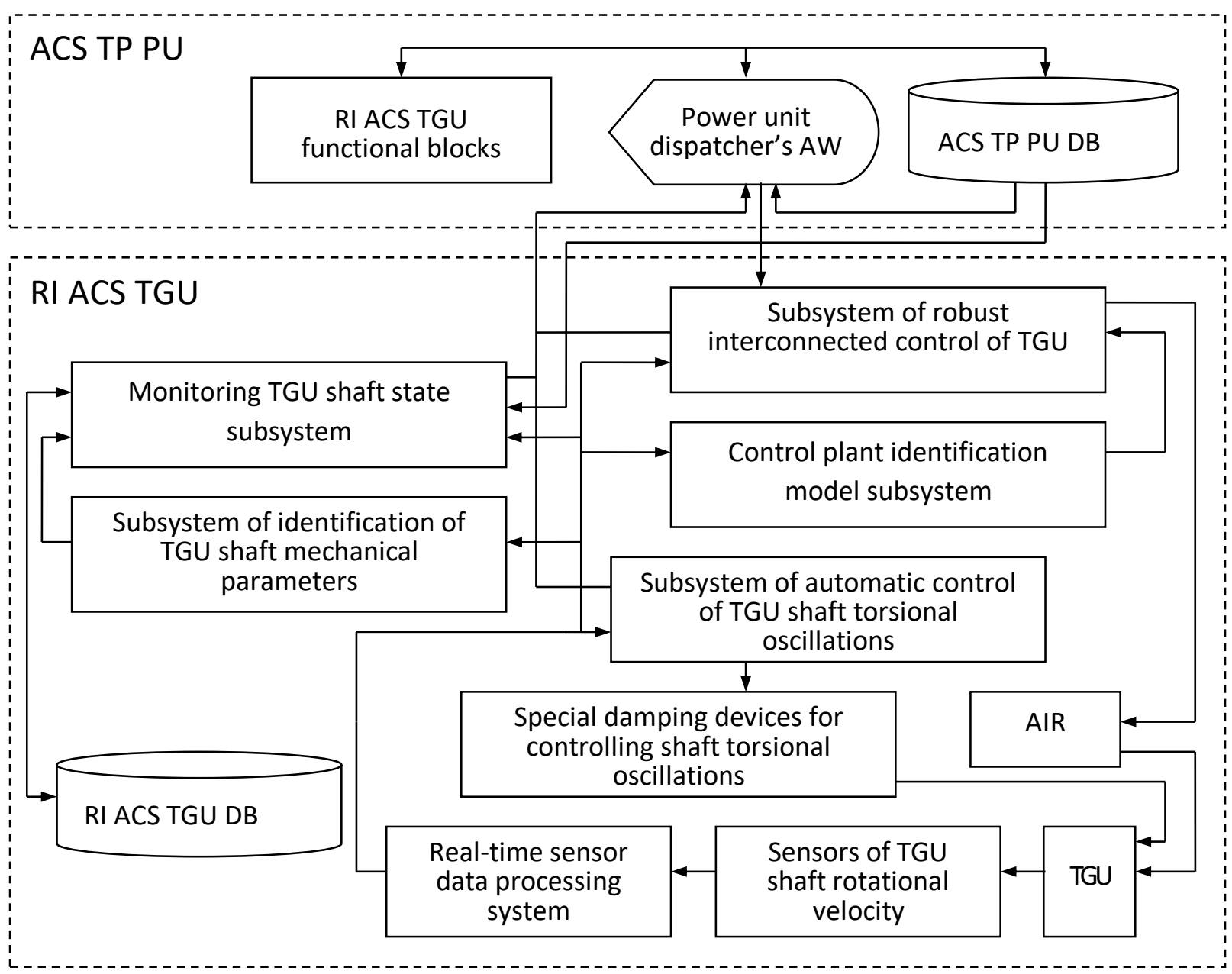

Figure 2. Functional structure of RI ACS TGU

One of the main tasks of the TGU shaft monitoring subsystem is to estimate the initial value of parameter D [9], which is a measure of fatigue damage of the shaft 
material according to Palmgren-Miner rule, to calculate it in real time, and to send information about its current status and exceeding the critical level to the power unit dispatcher. In its work the monitoring subsystem uses the data of the subsystem of identification of mechanical parameters of the TGU shaft [Error! Reference source not found.]. On the basis of the monitoring data of the shaft and the identification of parameters, the dispatcher, by established procedures, solves the issue of removal of TGU in repair, controls the state of transients in TGU.

The automatic TGU shaft torsion control subsystem also controls special damping devices for controlling shaft torsional oscillations [Error! Reference source not found.], which, due to their design, can create additional torque in a particular section of the shaft.

\section{Conclusions}

The solution of the problem of ensuring the durability and reliability of TGU operation in various transients in the power system is proposed by creating an automated system of robust interconnected control of TGU with the function of monitoring the state of the TGU shaft. Development of the TGU automated system of interconnected control consists in the organization of the multilevel control system taking into account the mutual influence of the generator's ECS and turbine's TGS subsystems, the use of local and centralized control systems. The designed system provides improvement of the TGU damping characteristics in conditions of uncertainty in the perturbations of power grid mode with the use of robust control methods, procedures for identifying parameters, monitoring the state of the shaft through the proposed methods of assessing the damage of its material.

\section{References}

1. Baliuta S.M., Kuievda Iu.V. (2018), Synthesis of robust interconnected system stabilizer for turbine generator units under uncertainty, Automatics-2018: materials of XXV International Conference of automatic control, 18-19 September 2018, Lviv, pp. 149-150.

2. Bovsunovskii A., Chernousenko O., Shtefan E., Bashta D. (2010), Fatigue damage and failure of steam turbine rotors by torsional vibrations, Strength of Materials, 42(1), pp. 108-113.

3. Bovsunovskii A. P. (2012), Torsional vibration in steam turbine shafting in turbogenerator abnormal modes of operation, Strength of Materials, 44(2), pp. 177-186.

4. Chen Y. at al. (2014), Study on power plant integrated excitation and turbine control strategies, International Conference on Power System Technology, 20-22 October 2014, Chengdu, IEEE, pp. 838-843. 
5. Kuievda Yu. V., Baluta S. M. (2017), Parameter identification method of the turbine-generator shaft elastic model for torsional vibrations simulation, Works of the institute of electrodynamics of the national academy of sciences of Ukraine, 47, pp. 37-44.

6. Kuievda Yu., Baliuta S. (2017), Synthesis of robust interconnected power system stabilizers for turbine generators in sugar factories, Ukrainian Journal of Food Science, 5(2), pp. 256-266.

7. Kuievda Yu., Kuevda V., Baluta S. (2017), Decreasing shaft swings of powerful turbogenerators by means of an asynchronous damping device, Works of the institute of electrodynamics of the national academy of sciences of Ukraine, 46, pp. $50-55$.

8. Kundur P. (1994), Power system stability and control, McGraw-hill, New York.

9. Liu Y., Mahadevan (2010), Probabilistic fatigue life prediction of composite materials, in Vassilopoulos A. (ed.) Fatigue Life Prediction of Composites and Composite, Woodhead Publishing, pp. 220-248.

10. Mayouf F., Djahli F., Mayouf A. (2013), Study of Excitation and Governor Power System Stabilizers Effect on the Stability Enhancement of a Single Machine Infinte-Bus Power System, 12th International Conference on Environment and Electrical Engineering, 2013, Wroclaw, IEEE, pp. 534-538.

11. Sarkar D. (2015), Thermal power plant: design and operation, Elsevier, Amsterdam; Boston.

12. Walker D. N. (2003), Torsional Vibration of Turbomachinery, McGraw-Hill Professional, New York. 